UNIVERSITY OF COPENHAGEN

The Google I decision in a nutshell

Bergqvist, Christian

Publication date:

2018

Citation for published version (APA):

Bergqvist, C. (2018). The Google / decision in a nutshell. 


\title{
The Google I decision in a nutshell
}

\author{
By associated professor Christian Bergqvist, ph.d. University of Copenhagen
}

On 18 December, the Commission - finally - published its June 2017 Google decision. It is highly suggested reading for the competition law legal community. The decision is noteworthy for its brevity at 216 pages, compared to the 518-page Intel decision (2009) 302-page Microsoft decision (2004). While the page count is surprisingly low, the significant fine of EUR 2.42 billion carries the weight of EUR 11.22 million per page. The decision's brevity largely results from the reduction of the original four (2010) charges down to one (see Recital 63) and that the new charges regarding Android (2015) will come in a separate decision. Thus, additional cases (and pages) are looming in the not so distant future.

\section{The tale of two markets with a vertical link}

The legal foundation of the decision is rather simple, and perhaps too simple. Two markets, both national in scope, are involved (Recital 154-263) involving: (a) general searches (horizontal) across the entire internet for whatever one enters in the search engine, and (b) comparison shopping that allows users to search for specific products/services and compare prices and characteristics across different online retailers. Moreover, there is a vertical link between the two as general searches can be used to locate suppliers of comparison shopping, and thus be considered upstream.

General searches are separated (Recital 161-190) from, e.g., (i) content sites as different newsgroups, (ii) online sales platforms such as Amazon, (iii) social media such as Facebook, and (iv) specialized searches such as www.kayak.com, which focus on travel and provide a vertical search for a specific subject matter. More important are general searches totally dominated by Google with an estimated above 90 percent market share in most EU countries. Comparison shopping (Recital 191-250) involves a service where users can compare products and prices directly on the Google platform instead of visiting different specialized online sites. This is a service distinct from (i) online merchant and merchant platforms, such as Amazon and eBay that actually sell products, (ii) specialized searches focusing on one subject matter, (iii) online search advertising platforms, and (iv) different online retailers. Google is active when it comes to comparison shopping with Google Shopping, but not much is offered regarding Google's market position here. In contrast, much effort is invested into explaining how Google dominates the former through strong network and bandwagon effects (Recital 285-315), thus entrenching Google near monopoly position and making it unlikely to challenge. However, the high market share largely follows mechanically from the narrow market definition.

I have mixed feeling about the rendered markets. I accept that general searches is something different from specialized searches, where the former offers a horizontal search across the entire internet and the latter, by contrast, offers a vertical search for one specific subject matter. On the other hand, Google Shopping bridges the two by allowing one to search for travels and books through a general (horizontal) search negating the need to use specialized (vertical) searches. Moreover, even after reading the decision several times, I still fail to understand how comparison shopping precisely is separated from general searches, as some of the functions are identical. Presumably, this matter will be discussed intensely before the General Court when that time comes.

\section{The theory of harmed advanced by the Commission - A bridge too far?}

The two markets (and ability to separate them) are essential for understanding the theory of harm advanced by the Commission. Essentially, this involves how the first market (general searches) is abused to leverage the strong market position to the second (comparison shopping). Not only for the purpose of securing control with a new (and more profitable) market, but also to prevent the latter from being used as a jumping off point for an attack on the former (see Recital 342). The merits of the leverage strategy are not well supported with internal documents (save some potential references in Recitals 381, 382, 390 and 643), and thus somewhat 
open-ended. Legally, of course this is immaterial - as abuse does not require malicious intent (as noted in recital 338). However, abuse requires (a) some sort of impediment to competition, and (b) meeting the legal requirements defined by the applicable abuse standard. Herein lies the decision's potential flaws. Of the 124 pages devoted to the question of abuse, the bulk explains how Google's behavior is detrimental to competition while (in my opinion) only 11 pages attempt remotely to explain how this meets the relevant legal requirements (Recital 331-339, 591-607 and 641-652).

In my opinion, the Commission never fully explains what legal standard the decision advances, except from rebutting that it is a refusal to supply (Recital 650). However, from the submitted arguments (see, e.g., Recitals 336 and 379) it is clear that the Commission feels that Google demotes searches that do not lead users to Google Shopping, and thus exclusionary discriminates. Moreover, this fits perfectly with the leverage strategy outlined above, but is more flawed when it comes to explaining how consumers are harmed. Comparison shopping is clearly a profitable activity in contrast to general searches, where the Commission has to offer some consideration on the matter (see, e.g., Recitals 157-160) making it rather logically why Google might attempt to divert traffic. The Commission is clearly not ignorant of this, as references (Recital 159) are made to the economics of two sides platforms.

\section{Discriminatory abuse is unchartered waters}

Of all possible legal standards, discrimination is presumably the most open-ended and unsettled, partly explaining why (help me if I have missed one) not a single case is invoked in direct support of the legal findings. All the cases cited (see, e.g., pp. 74-76 and 182-183) interprets the general principles of Article 102 rather than Article 102(c) on discrimination and how it should be applied directly to the case. Moreover, while presenting the behavior as discrimination, the word is never used nor are there any references to Article 102(c). Of course, case law - including new principles - can be developed. And, in light of the many calculations offered in support, the decision is not entirely unfound - provided, of course, the market description holds water. Moreover, it is somewhat unusual for the Commission to advance a decision, not to mention doling out the biggest fine ever, without having a basket of cases upon which to rely in support of why the demonstrated behavior clearly infringes Article 102 and generally accepted commercial practice. Consequently, there is much to be discussed before the General Court, including the inconsistencies noted above and some (claimed) irregularities in the proceedings (see Recitals 106-144). The latter will most likely haunt the Commission as they invoke (Recital 120) in support of its action, the now overturned General Court ruling in Intel.

\section{It's doubtful that Google has meet the order to terminate its abuse}

As a side note, the decision (p. 214) orders Google to present a solution to remedy its abuse within 90 days from June 2017 that meets defined requirements (summarized in Recital 700). If I understand Google's proposal (submitted in August) correctly, such solution involves securing equal access to displays in Google Shopping. However, as detailed above, the abuse does not relate to activities on the market for comparison shopping, but instead the upstream market for general searches. I'm therefore inclined to be scepticical on the remedies meeting the requirements and find it rather likely we soon will hear about a potential barrage of daily fines.

The decision is available using the link below and I welcome comments on cbe@jur.ku.dk regarding points I have missed or misread.

http://ec.europa.eu/competition/antitrust/cases/dec_docs/39740/39740_14996_3.pdf 